\title{
Evasão e Permanência dos Estudantes de um Curso de Administração a Distância do Sistema Universidade Aberta do Brasil: uma teoria multiparadigmática
}

\author{
Dropout and Students Abiding in an E-Learning Management \\ Course at Brazil Open University: a multiparadigmatic theory
}

Andressa Sasaki Vasques Pacheco

Doutora em Engenharia e Gestão do Conhecimento. Professora do Departamento de Ciências da Administração da Universidade Federal de Santa Catarina. Florianópolis, SC. Brasil. E-mail: andressa.pacheco@ufsc.br

\section{Marina Keiko Nakayama}

Doutora em Administração. Professora do Departamento de Engenharia do Conhecimento da Universidade Federal em Santa Catarina. Florianópolis, SC. Brasil.E-mail: marina@egc.ufsc.br

\section{Maurício Rissi}

Doutor em Engenharia e Gestão do Conhecimento. Universidade Federal de Santa Catarina. Professor da Aero TD - Faculdade de Tecnologia e Escola de Aviação Civil. Florianópolis, SC. Brasil. E-mail: mauricio.rissi@ufsc.br

\section{Resumo}

Esta pesquisa adota o método da Grounded Theory por causa da sua contribuição para o desenvolvimento de teorias e sua adaptabilidade ao campo de estudo, ao tema e aos objetivos. Dessa forma, foi realizado um estudo de caso qualitativo, tendo como foco de estudo o curso de Administração a distância da Universidade Federal de Santa Catarina. Foram feitas 60 entrevistas com os gestores, alunos e tutores. Para a análise desse estudo, foi utilizada a abordagem multiparadigmática, de acordo com os paradigmas interpretativista (predominante), funcionalista, teoria crítica (humanista radical e estruturalista radical) e a gestão do conhecimento. Fazendo uma avaliação da abordagem multiparadigmática utilizada, pode-se perceber que o paradigma mais atuante no curso é o funcionalista, por meio da busca da efetividade. Em relação à teoria fundamentada em dados desenvolvida, o ponto principal percebido foi a estrutura de gestão $e$ a variabilidade de opções disponibilizadas aos alunos.

Palavras-chave: Permanência. Evasão. Educação a Distância. Grounded Theory. Gestão do Conhecimento.

\section{Abstract}

This research adopts the Grounded Theory method, because the tool contribution to develop new theories, as the flexibility in the field, subject, and objectives. Thereby, it was performed a qualitative case study, in the management course in Santa Catarina Federal University. It was interviewed sixty managers, students and tutors. To analyses this study, it was used the multiparadigmatic approach, according to the interpretive paradigms (predominant), functionalist, critical theory (radical humanist and radical structuralism) and knowledge management. As results, it was able to perceive the functionalism paradigm predominance, related with an effective investigation. In relation the theory developed with the database, the main results were the management structure and the large amount of offered options to the students.

Keywords: Abiding. Dropout. E-learning. Grounded Theory. Knowledge Management. 


\section{INTRODUÇÃo}

A gerência e a administração eficientes requerem não apenas uma equipe competente, mas também sistemas e rotinas administrativas definidas e eficientes, além de sistemas de planejamento e monitoramento, de planejamento orçamentário e de prestação de contas que considerem critérios de desempenho. Esses sistemas podem ser diferentes nas organizações educacionais. (UNESCO, 1997)

Um dos problemas na gestão da educação diz respeito à evasão e à permanência dos alunos. Quanto a essa realidade no sistema educacional brasileiro, segundo Souza (1999), a evasão é apontada por vários pesquisadores como uma das suas maiores deficiências. Ainda que sejam poucas as pesquisas no Brasil sobre o fenômeno, a preocupação dos estudiosos é descobrir as principais causas da evasão, para proporem alternativas de solução visando elevar o número de estudantes que concluam seus cursos.

Corroborando com essa constatação, Biazus (2004) destaca que é importante verificar e levantar as razões (causas) contribuintes à evasão, com o intuito de minimizar o número dos acadêmicos que abandonam o ensino superior. Para o autor, isso poderia levar o curso a realizar uma avaliação constante, e, em especial, nas suas inter-relações com a comunidade, tendo em vista a busca da qualidade do ensino-aprendizagem e da sua responsabilidade com a sociedade de forma a diminuir os desperdícios. Em pesquisa afim, Cislaghi (2008) comenta sobre a necessidade de estudos específicos na área de $\mathrm{EaD}$.

A evasão universitária tem se caracterizado como uma realidade recorrente no âmbito do ensino de graduação, em várias partes do mundo. As formas de acesso e permanência dos alunos nos cursos superiores, especificamente na graduação, têm preocupado pesquisadores e gestores no mundo inteiro. (FARIA; ALCANTARA; GOIA, 2008)

Pacheco (2007) afirma que muitos dos fatores citados como dificultadores e que contribuem com a evasão advêm de uma carência oriunda de um modelo mental da modalidade presencial, ou seja, fatores como a falta de contato direto com professores, colegas e tutores trazem dificuldades aos alunos, levando-os a abandonar o curso. Para tanto, faz-se necessário uma gestão mais ativa de atividades presenciais e utilização de recursos que permitam atividades em grupo entre os estudantes, para que os mesmos não se sintam sozinhos e desmotivados.

Para Cislaghi (2008), o estudo do fenômeno da evasão discente em IES brasileiras ainda é uma área de pesquisa a ser desenvolvida e que, certamente, esse estágio inicial de conhecimento tem relação direta com a pouca atenção que é dada ao setor da educação.

Complementa-se que a gestão dos cursos a distância deve estar comprometida com a qualidade. A ampliação quantitativa da educação superior brasileira por meio dessa modalidade precisa vir acompanhada da qualidade do ensino, para gerar assim o desenvolvimento socioeconômico do país. (PACHECO, 2007)

Neste quadro de dificuldades para os países periféricos como o Brasil, as possibilidades de mudança, no sentido da democratização do acesso aos meios técnicos disponíveis na sociedade e da diminuição das desigualdades sociais, situam-se no nível das escolhas políticas da sociedade, ou seja, da capacidade de a escola e os cidadãos acreditarem - $e$ agirem consequentemente - em uma concepção dos processos de educação e comunicação como meios de emancipação e não apenas de dominação e exclusão. (BELLONI, 2002, p. 5)

Nesse sentido, percebe-se também que uma das deficiências encontrada no sistema educacional brasileiro, diz respeito ao seu alcance, principalmente tratando-se de ensino superior. A UNESCO (1997) ressalta que para minimizar essas deficiências, as instituições terão de estabelecer novas parcerias e alianças, para que possam atender as necessidades da sociedade de forma mais efetiva do que a maioria delas está conseguindo atender hoje. A experiência e a competência já adquiridas, em instituições de aprendizagem aberta e a distância, precisam ser aproveitadas ao máximo em futuras estruturas educacionais.

Para enfrentar esses desafios no Brasil, o conjunto das instituições participantes do Fórum das Estatais da Educação propôs a criação do Sistema Universidade Aberta do Brasil (UAB), que congrega instituições públicas de educação superior para ofertar cursos e programas da modalidade a distância, tendo como ponto de partida a consolidação e a diversificação de experiências, em variados níveis de ensino, que vêm gradativamente tomando forma no país. (ABRAEAD, 2007) 
Um dos projetos inseridos nessa ampliação do ensino é o projeto piloto em Administração. Esse projeto está presente em mais de 20 estados brasileiros, e é resultado de uma parceria entre a UAB (projeto pertencente ao Ministério da Educação - MEC) e o Banco do Brasil.

Em Santa Catarina, este curso teve início em julho de 2006, e foi destinado aos funcionários do Banco do Brasil, servidores da UFSC e outros servidores públicos da esfera federal, estadual e municipal. O curso iniciou suas atividades com 654 alunos, em dez polos espraiados pelo Estado de Santa Catarina: Araranguá, Canoinhas, Chapecó, Criciúma, Florianópolis, Joinville, Lages, Laguna, Palhoça e Tubarão.

Um dos problemas detectados no começo do projeto piloto foi a evasão. Em pesquisa anterior, foi percebida uma lacuna no estado da arte da educação a distância, em relação à evasão e a permanência dos estudantes, principalmente quanto à realidade brasileira, em específico na esfera pública. Além disso, considerando a complexidade desta organização, buscou-se a utilização de uma análise multiparadigmática, tentando desta forma conhecer mais amplamente esta organização.

Dessa forma, o objetivo desta pesquisa consiste em desenvolver uma construção teórica da gestão do curso de administração a distância da UFSC nos processos de evasão e permanência do estudante sob a ótica multiparadigmática.

\section{Procedimentos Metodológicos}

Inicia-se a discussão da Grounded Theory com um breve histórico:

\begin{abstract}
A metodologia, geralmente conhecida como teoria fundamentada, foi desenvolvida originalmente por dois sociólogos, Barney Glaser e Anselm Strauss (Glaser, 1978, 1992; Glaser e Strauss, 1967; Strauss, 1987). Embora cada um deles viesse de uma tradição filosófica e de pesquisa diferente, suas perspectivas contribuições foram igualmente importantes. (STRAUSS; CORBIN, p. 22)
\end{abstract}

Complementa-se que os objetivos e os processos fundamentais que caracterizam o método não se alteraram; e muito do que se escreveu sobre como avaliar uma boa Grounded Theory não aprimorou no livro de 1967. Strauss e Glaser divergiram sobre alguns pontos e o método dividiu-se em duas vertentes. Uma desenvolvida por Glaser e outra, por Strauss com colaboração de Juliet Corbin. (BANDEIRA DE MELLO; CUNHA, 2006)

Portanto, a vertente estudada e utilizada nesta pesquisa será de Strauss e Corbin, que segundo Bandeira de Melo e Cunha (2006), apresenta duas peculiaridades em relação à vertente glaseriana:

a) é mais prescritiva, ao sugerir uma série de procedimentos, técnicas e uma formatação mais estruturada para a teoria gerada;

b) é mais específica na delimitação da pesquisa.

Quanto a este último ponto, argumenta-se que

Glaser (1992) defende que o pesquisador deve delimitar o contexto e entrar no campo sem uma questão de pesquisa definida: ele deve permitir que o fenômeno a ser estudado seja inteiramente fiel à realidade dos sujeitos envolvidos. Como exemplifica Douglas (2003), enquanto na versão glaseriana a investigação em uma organização deveria iniciar-se com uma abordagem geral da gestão da firma - para depois especificarem-se questões - na versão de Strauss e Corbin, a coleta de dados poderia iniciar-se focalizando-se em uma questão específica, como a política de recursos humanos. (BANDEIRA DE MELLO; CUNHA, 2006, p. 244)

Cabe destacar que o objetivo dos autores da Grounded Theory (GT) é oferecer um conjunto de ferramentas úteis para analisar dados qualitativos, assim oferece um conjunto de procedimentos úteis - essencialmente diretrizes, técnicas sugeridas, mas não preceitos. Além disso, ajuda a desenvolver uma maneira diferente de pensar sobre a realidade social e estuda-la, como intuito de enriquecer a pesquisa. (STRAUSS; CORBIN, 2008)

Bandeira de Melo e Cunha (2006) complementam que a GT objetiva gerar explicações, com a mínima intervenção do pesquisador, sobre a ação dos indivíduos em um contexto delimitado, a partir da realidade deles: por que e como determinado grupo age, ou interage com outros grupos em situações contextuais específicas e delimitadas. 
Vários motivos levaram ao desenvolvimento dessa metodologia, sendo que Strauss e Corbin (2008) citam alguns desses:

a) a necessidade de sair a campo para descobrir o que está realmente acontecendo;

b) a relevância da teoria, baseada em dados, para o desenvolvimento de uma disciplina e como base para ação social;

c) a complexidade e a variabilidade dos fenômenos e das ações humanas;

d) a crença de que as pessoas são atores que assumem um papel ativo para responder a situações problemáticas;

e) a percepção de que as pessoas agem com base em significados;

f) o entendimento de que o significado é definido $e$ redefinido por meio da interação;

g) sensibilidade para a natureza evolutiva e reveladora dos fatos (processos); e

h) consciência das inter-relações entre condições (estrutura), ação (processo) e consequências.

Essa ideia é corroborada pela seguinte citação:

A fundamentação (grounded) da teoria nos dados conferia ao método as seguintes características (GOULDING, 2002): a) a necessidade de estar no campo para compreender a realidade dos indivíduos; b) a importância de fundamentar a teoria nessa realidade (e não em pressupostos teóricos); c) a natureza das experiências dos pesquisadores e sujeitos evolui continuamente; d) os sujeitos têm papel ativo em moldar a realidade que experimentam por meio da interação simbólica; e) a ênfase na mudança, no processo, na variabilidade e complexidade das experiências dos indivíduos; f) o relacionamento entre significado, na percepção dos indivíduos, e sua ação. (BANDEIRA DE MELLO; CUNHA, 2006, p. 242)

Agrega-se ainda que a relevância da GT é que esta garante um senso de visão, no qual o analista quer seguir junto com a pesquisa. Com isso, as técnicas e os procedimentos (método), por outro lado, fornecem os meios para transformar essa visão em realidade.

Outro importante ponto a ser destacado da GT, de acordo com Strauss e Corbin (2008), é o valor da metodologia está em sua capacidade não apenas de gerar teoria, mas também de basear essa teoria em dados. Tanto a teoria como a análise de dados envolvem interpretação, mas, pelo menos, é interpretação baseada em investigação feita sistematicamente.

Complementa-se ainda que

Eles querem dizer que foi derivada de dados, sistematicamente reunidos $e$ analisados por meio de processo de pesquisa. Neste método, coleta de dados, análise e eventual teoria mantêm uma relação próxima de si. Um pesquisador não começa um projeto com uma teoria preconcebida em mente (a não ser que seu objetivo seja elaborar e estender uma teoria existente). Ao contrário, o pesquisador começa com uma área de estudo e permite que a teoria surja a partir dos dados. A teoria derivada dos dados tende a se parecer mais com a realidade do que a teoria derivada da reunião de uma série de conceitos baseados em experiências ou somente por meio de especulação (como alguém acha que as coisas devem funcionar). (STRAUSS; CORBIN, 2008, p. 25)

Dessa forma, teorias fundamentadas, por serem baseadas em dados, tendem a oferecer mais discernimento, melhorar o entendimento e fornecer um guia importante para ação (STRAUSS; CORBIN, 2008). Várias são as opções de técnicas, métodos e pesquisas, por isso, cabe ao pesquisador delinear quais as melhores estratégias para sua pesquisa.

Sendo assim, esta pesquisa adota o método da Grounded Theory (GT), por perceber a contribuição desse método para o desenvolvimento de teorias e sua adaptabilidade ao campo de estudo, ao tema e aos objetivos. Sendo assim, serão utilizadas as técnicas descritas na explicação da Grounded Theory.

Bandeira de Melo e Cunha (2006) complementam que a GT objetiva gerar explicações, com a mínima intervenção do pesquisador, sobre a ação dos indivíduos em um contexto delimitado, a partir da realidade deles: por que e como determinado grupo age, ou interage com outros grupos em situações contextuais específicas e delimitadas.

Outro importante ponto a ser destacado da GT, de acordo com Strauss e Corbin (2008), é o valor da metodologia está em sua capacidade não apenas de gerar teoria, mas também de basear essa teoria em dados.

Dessa forma, foi realizado um estudo de caso qualitativo, que tem como foco de estudo o curso de 
Administração a distância da Universidade Federal de Santa Catarina. Justifica-se a escolha desse curso por causa do acesso a informações, da experiência profissional, do pioneirismo e do destaque que ele vem ganhando nacionalmente.

Para a análise deste estudo, foi utilizada a abordagem multiparadigmática. Dessa forma, foi feita uma interpretação de Lewis e Grimes (2007), utilizando paradigmas e teorias para analisar os dados da pesquisa. Com isso selecionou-se as seguintes visões de mundo: interpretativista, funcionalista, teoria crítica (humanista radical e estruturalista radical) e a gestão do conhecimento. Tais visões serviram de base para análise, acarretando no desenvolvimento de uma teoria multiparadigmática sobre a realidade do estudo de caso. Assim, buscou-se delimitar não só o que estava de acordo com cada paradigma, mas também as divergências encontradas.

Sobre os paradigmas utilizados, destaca-se que o paradigma interpretativista foi o principal utilizado na pesquisa, devido a sua inter-relação com o método escolhido, Grounded Theory, e à necessidade de seu uso para análise dos dados. Esse paradigma foi essencial na formulação das categorias, das subcategorias e das suas propriedades e dimensões, pois essas classificações advêm da interpretação dos dados coletados.

Já o paradigma funcionalista esteve relacionado às teorias de gestão, já que é essa a área da pesquisadora e do estudo de caso em questão, sendo necessário sua análise para entender algumas questões $e$ atitudes. Para isso, buscou-se nas entrevistas um foco na eficiência e eficácia do curso, elementos essências no paradigma funcionalista.

A teoria crítica vem corroborar com o entendimento mais crítico da gestão e trouxe questões de análise emancipatórias. A base utilizada está nas ideias de Habermas (2007a, 2007b, 2003, 2002) (agir comunicativo), Pedro Demo (2004) (autoridade do argumento), Vygotsky (2009), Piaget (1970) e Paulo Freire (2006, 2001, 1992, 1970) (agir educacional). Dessa forma, busca-se uma análise crítica em relação à formação que o aluno está desenvolvendo, não apenas academicamente, mas também socialmente.
Espera-se também analisar, por meio do paradigma da gestão do conhecimento, os tipos de conhecimento e como eles são compartilhados e disseminados na organização. Pretende-se alcançar não apenas uma gestão efetiva, mas voltada também para a aprendizagem organizacional e para os processos vislumbrando a gestão do conhecimento.

Com isso, pode-se traçar um quadrante (Quadro 1) com os paradigmas essenciais a esta pesquisa, bem como os principais conceitos inerentes a cada um deles.

\begin{tabular}{|c|c|}
\hline INTERPRETATIVISTA & FunCIONALISTA \\
\hline $\begin{array}{l}\text { As organizações são } \\
\text { processos que surgem das } \\
\text { ações internacionais das } \\
\text { pessoas, individualmente ou } \\
\text { em harmonia com outras } \\
\text { (VERGARA; CALDAS, 2007) }\end{array}$ & $\begin{array}{l}\text { Efetividade = eficiência } \\
+ \text { eficácia } \\
\text { as organizações são objetos } \\
\text { tangíveis, concretos e objetivos } \\
\text { (VERGARA; CALDAS, 2007) }\end{array}$ \\
\hline TEORIA CRÍTICA & Gestão do Conhecimento \\
\hline $\begin{array}{l}\text { Agir educacional e } \\
\text { autonomia (FREIRE, 2006, } \\
\text { 2001, 1992, 1970) } \\
\text { Agir comunicativo } \\
\text { (HABERMAS, 2007a, } \\
\text { 2007b, 2003, 2002) } \\
\text { Autoridade (DEMO, 2004) }\end{array}$ & $\begin{array}{l}\text { Espiral do conhecimento } \\
\text { (NONAKA,TAKEUSHI; 1997) } \\
\text { Armazenamento e } \\
\text { compartilhamento } \\
\text { Condições Capacitadoras da } \\
\text { Criação de Conhecimento } \\
\text { Organizacional } \\
\text { (NONAKA,TAKEUSHI; 1997) }\end{array}$ \\
\hline
\end{tabular}

Quadro 1: Arcabouço teórico e paradigmas Fonte: Elaborado pelos autores deste artigo

Quanto à temporalidade da pesquisa, delimitou-se a coleta de dados de julho de 2009 a janeiro de 2010. Cabe ressaltar que as percepções dos entrevistados podem ter sido influenciadas por períodos anteriores, desde o início dos cursos a distância em 2006. Dessa forma, os dados pesquisados podem representar a realidade do começo do curso, em julho de 2006 até janeiro de 2010.

A seguir, será apresentada a estruturação do desenvolvimento desta pesquisa.

\subsection{Fluxograma da Pesquisa}

Apresenta-se um fluxograma (Ilustração 1), com as principais etapas da pesquisa, suas decisões, de acordo com os conceitos delineados na Grounded Theory, lembrando que a busca final desta pesquisa é uma teoria baseada no estudo do curso de Administração a distância da Universidade Federal de Santa Catarina. 


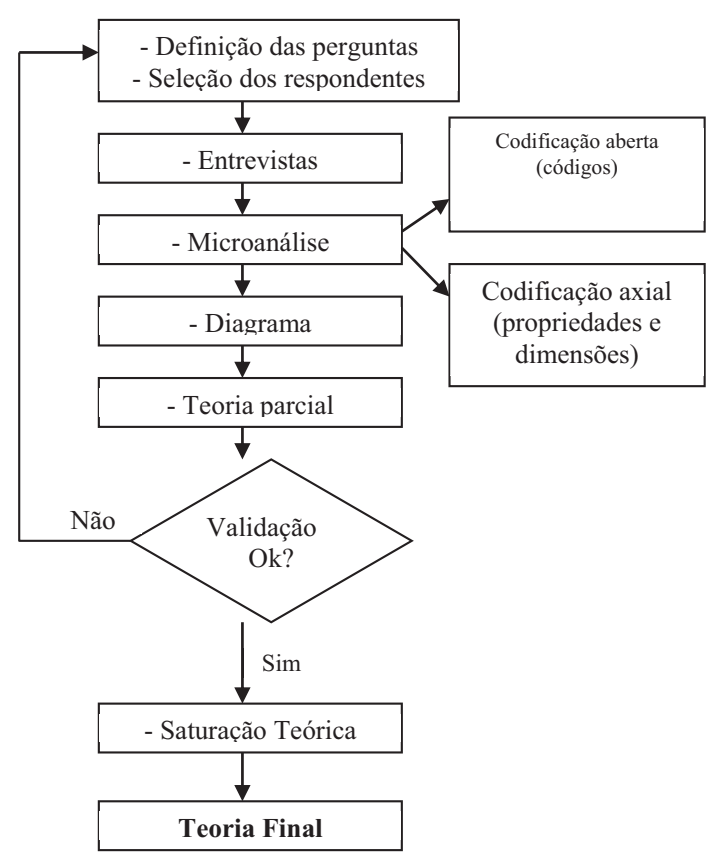

Ilustração 1: Fluxograma da pesquisa

Fonte: Elaborada pelos autores deste artigo

Em relação ao tratamento de dados utilizados, seguiu-se a sugestão da Grounded Theory de Strauss e Corbin (2006). Com as primeiras questões delineadas, passa-se a escolha do público, que deve estar coerente com as perguntas a serem feitas. Nesse ponto foi levado em consideração o acesso aos respondentes e sua experiência no curso.

As entrevistas foram transcritas literalmente $e$ inseridas no software Atlas TI. Começa-se a microanálise. A primeira análise realizada foi a codificação aberta das entrevistas, selecionando, dessa forma, os códigos (criados pela autora da pesquisa ou in vivo), as citações (quotes) e fazendo comentários e anotações quando necessário (memos).

Após essa etapa, passou-se a codificação axial da pesquisa, ou seja, a partir dos códigos gerados na codificação aberta, foi feita uma seleção, e uma categorização, em um processo de relacionar categorias às suas subcategorias, associando também as categorias às suas propriedades e dimensões. Vale ressaltar que essa também faz parte da microanálise.

Dessa forma, foi desenhado um quadro com tais categorias, subcategorias, propriedades e dimensões. Esse quadro será o primeiro item a ser relatado na pesquisa. Com isso, pretende-se que o leitor tenha uma visão geral de todas as categorias.

Com a leitura das respostas dos entrevistados, é possível ter uma análise interpretativa do processo, apresentando, a seguir, a próxima etapa realizada, o delineamento do diagrama de relações, utilizando as categorias e os demais códigos advindos da codificação aberta.

Aprofundando a interpretação desse diagrama, apresenta-se no tópico subsequente uma visão multiparadigmática do estudo de caso, envolvendo os paradigmas: funcionalista, da teoria crítica e da gestão do conhecimento. Procura-se, assim, delinear a teoria substantiva a este estudo de caso.

Essa teoria é validada com especialistas do assunto ou mesmo os agentes envolvidos no campo, sendo essa opção a escolhida nesta pesquisa. Caso o pesquisador e os validadores considerem a pesquisa completa, há a teoria final, caso contrário, todo o processo é repetido, com novas entrevistas, microanálises, etc.

Nesta pesquisa foram necessárias 58 entrevistas até alcançar a saturação teórica e desenvolver a teoria final.

\subsection{Amostragem Teórica}

Em relação à amostragem teórica, como comentado por Strauss e Corbin (2008), na Grounded Theory não é delimitada exatamente quais e quantos serão os elementos da amostragem. Utilizando o fato de experiência e o conhecimento sobre o objeto de análise, pôde-se delinear alguns potenciais entrevistados para a pesquisa, sendo que o número de entrevistados dependerá da saturação teórica encontrada.

Sendo assim, os elementos da amostragem foram: ex-coordenador de curso, coordenador de curso, subcoordenador de tutoria, coordenador de polo, supervisores de tutoria, tutores a distância (em Florianópolis), tutores presenciais (em cada polo de ensino), alunos evadidos, alunos frequentes e coordenadores de polo.

Todos os nomes dos entrevistados são sigilosos, utilizando para efeito de divulgação da pesquisa uma codificação, por exemplo, Aluno 1, Aluno 2, Polo 1, Polo 2, etc. Em relação aos tutores a distância, aos supervisores e aos gestores do curso, eles foram renomeados como Tutor 2, Tutor 3, Gestor 3, etc. 


\begin{tabular}{|c|c|c|}
\hline Agentes & TOTAL & Codificação \\
\hline Alunos frequentes & 36 & $\begin{array}{l}\text { Aluno 1, Aluno } \\
2 \ldots \text { Aluno } 36\end{array}$ \\
\hline Alunos evadidos & 11 & $\begin{array}{c}\text { Evadido 1, Evadido } \\
2 \ldots \text { Evadido } 11\end{array}$ \\
\hline Polos & 3 & Polo 1, Polo 2, Polo 3 \\
\hline Tutores & 4 & $\begin{array}{l}\text { Tutor } 1 \text {, Tutor } 2 \text {, } \\
\text { Tutor } 3 \text {, Tutor } 4\end{array}$ \\
\hline Supervisores/Gestores & 4 & $\begin{array}{l}\text { Gestor 1, Gestor 2, } \\
\text { Gestor 3, Gestor } 4\end{array}$ \\
\hline
\end{tabular}

Quadro 2: Entrevistados e codificação

Fonte: Elaborado pelos autores deste artigo

Os dados foram coletados por meio de entrevistas semiestruturadas, sendo que os instrumentos foram modificados durante a pesquisa, de acordo com as análises feitas em cada entrevista, ou seja, não houve instrumentos únicos e fixos para todos os entrevistados.

No caso dos alunos, a escolha dos entrevistados foi aleatória, de acordo com a lista de alunos fornecida pelo curso. Buscou-se encaminhar a solicitação para responder às perguntas do maior número possível de pessoas, devido à dificuldade de respostas por e-mail.

Dessa forma, foram feitas 60 entrevistas com o público-alvo, sendo que, na visão do pesquisador, foram suficientes para alcançar a saturação teórica deste caso. As entrevistas com coordenadores, tutores a distância e supervisores foram realizadas pessoalmente, gravadas e transcritas posteriormente. Já as entrevistas com os alunos, coordenadores de polo e tutores presenciais foram realizadas com o auxílio de tecnologias, como e-mail e mensagens instantâneas. Todas as entrevistas estão em formato digital para posterior consulta conforme necessidade.

A análise dos dados foi feita no Software para pesquisa qualitativa Atlas TI, desenvolvido com o intuito de auxiliar a construção de teorias, permitindo auditorias para se verificar a validade e confiabilidade dos resultados.

Por fim, destaca-se que a validação da pesquisa, a qual foi realizada com dez pessoas envolvidas com o curso em questão (coordenadores, supervisores, alunos, coordenadores de polos, sendo entrevistadas tanto pessoas participantes do momento atual do curso, como pessoas que já deixaram suas funções). Foi solicitada a leitura do documento com a descrição da teoria substantiva, e os entrevistados corroboraram com os resultados alcançados.

\section{Curso de Administração a Distância da Universidade Federal de Santa Catarina (UFSC)}

De acordo com o projeto pedagógico, o objetivo geral do curso de graduação em Administração a distância ministrado pela UFSC é o de formar o profissional administrador para atuar na micro, na pequena e na média empresa (pública e privada); ter capacidade empreendedora e analítica para elaborar diagnósticos; propor mudanças, ter visão sistêmica e, finalmente, conduza dentro da ética as empresas no atendimento das necessidades da sociedade.

Depois do concurso vestibular realizado em março de 2006, realizado pela Comissão Permanente de Vestibular (Coperve) alcançou-se um número de 654 matriculados, após sete chamadas. Entre eles encontram-se funcionários do Banco do Brasil (50\% dos estudantes) e servidores públicos federais, estaduais e municipais atuando em órgãos situados no Estado de Santa Catarina e portadores de diploma de ensino médio.

Quanto à dinâmica do curso, estabeleceu-se que cada ano é composto de dois módulos, sendo um por semestre. Os estudos têm como referência básica o material impresso, o ambiente virtual de aprendizagem, as videoaulas, as videoconferências com os professores e o sistema de acompanhamento ao estudante (tutoria).

O curso conta com a seguinte estrutura: um Coordenador de Curso; um Coordenador de Tutoria; um Coordenador Acadêmico; um Coordenador Financeiro, um Coordenador Editorial; um Coordenador dos Polos; e um Coordenador para cada Polo. Além disso, há também: subordinado ao coordenador de tutoria, dois Tutores Supervisores, 18 Tutores a Distância e dez Tutores Presenciais; com o coordenador acadêmico atua um secretário do curso; o coordenador financeiro conta com um assistente administrativo; a equipe editorial é formada por quatro professores revisores (Conselho Editorial), três diagramadores; dois revisores de português; um técnico; um supervisor e o coordenador editorial. 
Ao final do primeiro módulo, o curso apresentou um índice de evasão próximo a 30\% (199 estudantes), preocupando assim a coordenação deste curso. Com isso foram delineadas pela coordenação do curso $e$ da UFSC algumas ações para o resgate desses alunos, juntamente com um sistema de apoio para que esses estudantes pudessem recuperar as disciplinas que por ventura não tivessem cursado.

Foi concedido um período de reajuste para matrícula em caráter excepcional, sendo os alunos comunicados por e-mail. Esse fato foi justificado devido ao curso ser um projeto piloto, estando ainda em fase de organização e aperfeiçoamento.

Um dos parceiros desse curso, o Banco do Brasil, atuou ativamente nesse processo, fazendo contato direto com todos os seus funcionários que por ventura tivessem abandonado o curso.

Obteve-se como resultado o retorno de 89 estudantes, sendo que foi formada uma equipe de tutores para o atendimento e acompanhamento desses alunos. Após essas ações corretivas, o curso passou a um índice de evasão de $16,82 \%$, ou seja, 110 alunos. Atualmente, o curso encontra-se no $8^{\circ}$ módulo, com 446 alunos ativos, ou seja, um índice de evasão de $32,11 \%$.

É importante ressaltar que o curso coloca à disposição dos alunos uma estrutura bastante extensa, possibilitando facilidades para que eles possam estudar da melhor forma possível, preocupando-se essencialmente com seu aprendizado. Essa estrutura pode ser observada, por exemplo, em cada um dos polos de ensino que conta com Laboratório de Informática; Sala de Videoconferência; Sala de Estudos; Biblioteca. O curso ainda oferece material didático, composto por livro-texto para cada disciplina, totalmente gratuito e entregue ao aluno no seu respectivo polo, Ambiente Virtual de Ensino-Aprendizagem (AVEA) com textos complementares, videoaulas da disciplina, exercícios obrigatórios e complementares, indicação de bibliografia básica e complementar. As videoaulas também são disponibilizadas em CDs. Além da biblioteca dos polos, o aluno EaD tem à sua disposição a Biblioteca Universitária, nela, ele pode fazer uso por reserva e remessa por correio, já que a universidade paga o envio ao aluno e este paga o envio de volta à universidade.

O aprofundamento do estudo de caso na Grounded Theory é fundamentado nas falas dos atores sociais. Conforme descrito na metodologia foi utilizada a sequência sugerida por Strauss e Corbin (2006), mas neste artigo tem-se pouco espaço para a explanação detalhada desta pesquisa. Com isso, a seguir apresenta-se uma compilação dos dados no capítulo denominado teoria multiparadigmática.

\subsection{Teoria Multiparadigmática}

Por meio dos diagramas, das abordagens e das análises realizadas traçou-se as interpretações, os pensamentos e os resultados apresentados neste capítulo. Uma das principais buscas dos autores que estudam evasão são os fatores que levam a este fenômeno. Foi percebido que não há fatores comuns a todos os evadidos, e cada caso é uma particularidade. Isso não inviabiliza esta pesquisa, ao contrário, faz com que se tenha cuidado e estudo mais aprofundados de como minimizar esses fatores, levando em consideração a característica de cada curso, turma, região, etc.

Uma das classificações utilizadas quanto ao estudo da evasão são os fatores internos e externos à instituição. Os fatores externos não têm como ser controlados, mas os fatores internos podem ser amenizados ou eliminados por meio de uma gestão mais eficiente e eficaz. Mesmo não podendo ser controlados, os fatores externos podem ser conscientizados por meio de ações com os alunos, por exemplo, com um desenvolvimento do aproveitamento e planejamento do tempo dos estudantes.

Traz-se ainda a discussão sobre a adesão $e$ a permanência dos alunos, a qual deve ser pautada em uma perspectiva de qualidade do curso. Esse ponto é importante destacar, pois não se pretende buscar neste trabalho a gestão para um resgate quantitativo de alunos. Incorporando principalmente as indagações da teoria crítica de Freire, Demo, Piaget, entre outros, a busca é pelo aprimoramento do curso em relação à qualidade.

Mas, quais pontos devem ser tratados pela gestão? Qual a visão dos alunos, gestores e tutores desse processo? Por meio dessas visões, foi possível descrever e desenvolver uma teoria para a gestão de cursos a distância, com o intuito de minimizar a evasão.

Ressalta-se ainda que foi incorporada uma visão multiparadigmática, por meio da teoria funcionalista, da gestão do conhecimento, do agir educacional e comunicativo. A interpretativista, já está inerente ao 
método utilizado. Com isso, espera-se uma complementaridade de diferentes visões de mundo em um ambiente de alta complexidade.

O primeiro ponto a ser tratado é sobre a experiência e as dificuldades da gestão. A educação a distância na esfera pública, apesar de algumas iniciativas anteriores, teve seu maior desenvolvimento na última década. Essa "novidade" nas universidades mudou o panorama dos cursos e trouxe uma mudança significativa em sua estrutura e nas suas atividades.

Diante dessas mudanças não houve um preparo necessário, um treinamento ou mesmo uma orientação. Em muitos casos, o método de "tentativa e erro" foi o mais utilizado, mas desde esse momento analisa-se, na perspectiva da gestão do conhecimento, o que pode ser aprimorado. Se esse foi o método utilizado, o armazenamento dessas tentativas é essencial, bem como o compartilhamento desses fatores entre instituições. Essa troca de experiência ainda é pouco desenvolvida e acaba ocorrendo em diversas instituições, já que o erro de uma bastaria para que outras não o cometessem novamente.

Vale ressaltar que essa troca também não deve acontecer dentro da própria instituição entre os cursos na modalidade a distância. Talvez uma iniciativa institucional seja necessária para estimular essa troca de experiências.

Dessa forma, os fóruns e os seminários entre instituições devem ser constantes, mas não só com casos de sucessos, mas também com as falhas, os erros e as soluções encontradas. Talvez esse seja um dos grandes desafios para o desenvolvimento do conhecimento da educação a distância no Brasil (mas nem sempre é fácil expor seus erros e defeitos).

Além disso, é necessário, ainda, logo após essas atividades, criar eventos internos, cujos conhecimentos adquiridos por um grupo de participantes possam ser repassados a equipe da instituição. O desenvolvimento deve ser coletivo e não somente individual.

Pode-se perceber também que alguns problemas enfrentados decorrem da falta da institucionalização da educação a distância nas universidades. A peculiaridade da $\mathrm{EaD}$ não permite que sejam repassadas todas as regras universitárias da mesma forma que o presencial. E isso não pode acontecer após os cursos estarem em andamento. É o primeiro passo a ser dado quando se inicia ou se pretende implementar a
EaD nas instituições. Os cursos precisam ter respaldo da instituição nas suas decisões e, para isso, saber os limites e a flexibilidade que existem.

Outra dificuldade detectada foi na preparação e envolvimento dos professores na EaD. Foram feitas algumas tentativas de treinamento, mas com pouco desenvolvimento. Talvez devido à carga horária já delineada durante alguns anos, essa carga extra trouxe algumas resistências. Tem-se ainda a questão de a estrutura de preparação de aula, de o material didático e de os exercícios serem diferentes do presencial, e essa transição não era percebida por uma parte dos professores.

Além disso, há a dificuldade em compartilhar um trabalho, antes individual, com outros inúmeros agentes, como tutores, coordenadores e a comissão editorial, todos esses atores interferem no trabalho final, tendo, dessa forma, uma resistência por parte de alguns professores. Mas essa intervenção torna-se necessária devido à existência de certa padronização na $\mathrm{EaD}$, como no material didático por exemplo.

Neste ponto é necessário a atuação de uma equipe com conhecimento nos processos de um curso de EaD. Essa equipe deve auxiliar o professor desde a produção do material, até o uso do ambiente virtual e na preparação das atividades. No curso estudado, o contato inicial se dá com a coordenação do curso e a equipe editorial para a produção do material didático. Com isso pronto, a coordenação e a supervisão de tutoria apresentam as instruções gerais do funcionamento e quais são as atividades a serem realizadas pelos professores. Nota-se ainda que em algumas literaturas, os agentes da educação a distância são o professor, o tutor, o aluno e o gestor, mas essa visão é muito simplista e neste estudo tenta-se ampliar um pouco mais essa estrutura.

Outro agente incorporado à estrutura dos cursos de EaD são os supervisores de tutoria. O atendimento de tutoria é essencial para o bom funcionamento do curso, principalmente de acordo com a percepção do aluno, pois são os tutores que estão em contato direto com os alunos. Alguns cursos optam por tutores presenciais, outros por tutores a distância. Os tutores presenciais propiciam um contato mais direto com o aluno, mas dependendo do curso e das disciplinas, o seu treinamento e a homogeneidade das informações ficam prejudicados. Já os tutores a distância tem a 
facilidade de estarem mais próximos dos professores e coordenadores, mas seus contatos acontecem normalmente por e-mails ou ambiente virtual.

A escolha do tipo de tutoria vai depender do curso, dos recursos e da estrutura, entre outros fatores. No estudo analisado, utiliza-se um misto entre tutores presenciais e tutores a distância. Os tutores presenciais não são responsáveis pelo conteúdo, e sim por questões mais administrativas do acadêmico, como falta em provas, entrega de apostila, acompanhamento em provas e videoconferências, entre outros. Já a tutoria a distância está situada na sede da Universidade, com os tutores divididos em três turnos, atendendo 12 horas por dia (de segunda a sexta-feira). Na literatura encontra-se o papel do coordenador de tutoria, normalmente um professor com experiência em EaD que auxilia os tutores.

No caso deste curso, devido ao número de horas de atendimento e ao número de alunos e projetos simultâneos, foi criada a função de tutor supervisor. Essa função é exercida normalmente por ex-tutores, que têm experiência em $\mathrm{EaD}$ e que possuem características específicas, como liderança, responsabilidade, comprometimento, pró-atividade, entre outros. Esse supervisor tem maior autonomia do que o tutor e reporta suas ações ao coordenador, o qual exerce uma atividade mais gerencial/estratégica.

As funções dos tutores e supervisores foram mapeadas e delineadas pela coordenação do curso. Esse mapeamento auxiliou na formação de novos supervisores, mas novamente um problema percebido é o não armazenamento das decisões recorrentes, tendo assim perda de tempo com problemas com soluções já concebidas. Nas entrevistas foi percebido ainda que, mesmo com o mapeamento de processos, os supervisores têm dificuldade em acompanhar todas as atividades inerentes ao cargo, pois algumas não estão mapeadas, além de julgarem a capacitação para essa função pouco produtiva.

Os tutores ressaltam ainda a importância da supervisão e a existência de um pouco de flexibilidade em seu gerenciamento. A rotatividade dos tutores é alta, principalmente devido ao baixo salário em relação ao nível de escolaridade exigido e a não existência de garantias trabalhistas. Assim, para que o ambiente de trabalho seja favorável à motivação dos tutores, os supervisores precisam estar em constante atenção às suas necessidades.

Outro problema que os supervisores podem auxiliar é na comunicação entre os turnos de tutoria, pois no momento são três turnos de 4 horas de trabalho, enquanto os supervisores têm turnos de 6 horas. Esse número maior de horas possibilita que haja um elemento de coesão entre os tutores para favorecer a comunicação e as decisões tomadas.

Percebeu-se um problema na comunicação entre esses agentes: por se tratar de uma função operacional e gerencial, é necessário que eles entendam o contexto das decisões, para explicar mais claramente aos tutores. Houve relatos de que são emitidas ordens sem explicações, o que acaba gerando uma não legitimidade dessas ações pelos supervisores e tutores, por não entenderem o contexto.

Assim, houve solicitações por parte dos tutores de a ação comunicativa fosse mais desenvolvida. Esse fato é percebido na fala de um dos coordenadores, o qual solicita que os tutores não apresentem apenas os problemas, mas também as sugestões. Mas essa não pode ser uma ação isolada, é necessário que os tutores tenham liberdade para expor suas ideias e contestações sem sofrerem represálias devido a esse fato. Nos primeiros anos, eram realizadas reuniões semestrais para que cada tutor expusesse sua opinião sobre os problemas do curso e da tutoria, mas essas ações não tinham atitudes posteriores, levando a uma descrença nessa atividade.

Esses momentos de interação podem auxiliar no desenvolvimento da gestão do conhecimento, por meio da espiral do conhecimento de Nonaka e Takeushi (1997), com o compartilhamento, a internalização, a externalização e a socialização do conhecimento.

Além disso, incorporando os pensamentos de Habermas, as reuniões serviriam para a busca do entendimento e não somente convencimento de certa atitude. Isso auxilia na legitimidade das ações e no aprimoramento da gestão.

Retomando o assunto da rotatividade de tutores, esse é um fator relatado pelos alunos como dificultador aos seus estudos, principalmente quando acontece a troca durante uma disciplina. No início do curso, os tutores são selecionados entre os alunos das últimas fases do curso presencial, mestrandos e doutorandos. Com essa atividade, a rotatividade durante um semes- 
tre era baixa. Devido às novas exigências do MEC, os tutores passaram a ser selecionados com curso superior completo, com experiência em EaD, atividades de ensino ou mestrado. O pagamento desses tutores é por meio de bolsa FNDE, no valor de $\mathrm{R} \$ 600,00$ (seiscentos reais).

Devido ao baixo valor da bolsa em relação ao grau de escolaridade exigido, a troca da tutoria por outra oportunidade é constante no curso. Esse é um fato externo à instituição, que pode reivindicar, mas não mudar diretamente; no entanto, algumas ações podem ser tomadas para minimizar os efeitos dessa troca.

Primeiramente, sugere-se manter um banco de dados constante de possíveis candidatos à vaga de tutores; oferecer cursos gratuitos de tutoria à comunidade, para que na seleção alguns candidatos possam já ter conhecimento da função que irão exercer, que, depois de oferecidos durante certo período de tempo, podem ser exigência obrigatória ter cursado algum deles ao se candidatar a vaga de tutor.

Candidatos pré-selecionados podem também receber um treinamento das atividades da tutoria, do ambiente virtual e das características dos cursos. Isso faria com que ao se trocar os tutores, já se tenha previamente um candidato apto a começar no cargo, devendo somente ser dada a capacitação da disciplina em vigor.

O curso ainda estimularia os tutores a participarem de outras atividades de tutoria oferecidas em cursos de capacitação (de curta duração) além de uma especialização na instituição. Pode-se ainda, nesse sentido, estimular a participação em projetos e em outras atividades relacionadas à academia, como a produção de artigos científicos.

Relata-se ainda um dos sistemas de informação utilizado no curso. O software (Ambiente Virtual) recomendado pelo Governo Federal contém ferramentas pedagógicas e de comunicação, mas o controle gerencial nesse ambiente é inexistente, tendo-se que utilizar plataformas paralelas para se ter algumas informações.

Nesta instituição estudada, o ambiente virtual Moodle está agregado ao aplicativo de controle acadêmico da universidade, denominado CAGR. Antes dessa ação, era necessário fazer o repasse manual das notas de um ambiente ao outro. Essa foi uma ação institucional, mas que necessita ser ampliada para gerar relatórios e informações referentes à educação a distância. Relatórios como: quando o aluno vai ao polo, se participa de grupo de estudo, se participa de videoconferências, entre outros.

Outro ponto discutido com os entrevistados diz respeito à qual forma de gerenciamento seria mais adequado ao curso, um sistema rígido ou flexível. Não se trata neste ponto de trabalhar nos extremos, mas sim no melhor equilibrio entre as duas formas.

$\mathrm{Na}$ teoria da educação a distância fala-se constantemente da flexibilidade que essa modalidade deve proporcionar ao aluno. Mas é importante descrever $e$ delimitar essa flexibilidade para não ser confundida com falta de limites. Em um curso de graduação, como tratado neste artigo, as disciplinas têm período de oferta, no qual o professor está à disposição da tutoria, o ambiente virtual é desenvolvido para o período daquela disciplina, entre outras atividades. Se certa atividade tem uma semana para ser feita, o aluno terá a flexibilidade de escolher o melhor momento durante essa semana para ler o material, assistir a videoaula, tirar dúvida com o tutor e fazer o exercício. Percebe-se assim que há uma flexibilidade, mas com limite de tempo. Exceder aquela semana seria extrapolar os limites possíveis de flexibilidade prejudicando o bom funcionamento do curso.

Na visão de alguns alunos, caso haja flexibilidade excessiva, isso pode gerar problemas no seu aprendizado, falta de rotina de estudo e desmotivação durante o curso, por não ter desafios e sentir que está muito fácil.

Gerencialmente, devido a recursos financeiros, materiais, tecnológicos, de pessoas e ao desenho do curso, é impossível dar total flexibilidade aos alunos. E isso deve ser explicado desde o começo, pois a educação a distância muitas vezes é erroneamente difundida como uma modalidade mais fácil e de menos qualidade.

Qualidade, aliás, é um dos pontos frequentemente discutidos por alunos, professores, gestores $e$ pesquisadores da EaD. Em cursos com 500, 1.000 ou 1.500 alunos, é necessário uma gestão ativa para que se consiga alcançar e manter um patamar de qualidade. É necessário desenvolver um sistema rígido, não no sentido de extremamente burocrático e fechado, mas rígido em relação a ter delimitado os processos, as atividades de cada pessoa dentro da organização. Rígido no sentido de planejar e de controlar o que foi planejado. 
É importante destacar que para alcançar a eficácia do curso, é necessário que todos tenham consciência de que o objetivo é qualitativo, quantitativo ou uma combinação de ambos. Pôde-se perceber que não são todos os agentes que têm essa definição clara. Alguns tutores relataram, por exemplo, que há muitas facilidades (regalias) aos alunos, o que em alguns casos pode comprometer a qualidade do ensino. A gestão, mesmo com um discurso de visão qualitativa do curso, toma, em alguns casos, atitudes que visam mais a um objetivo quantitativo, ou seja, formar mais alunos em contraponto à qualidade dos formados. Esse fato pode ser esclarecido por meio da definição dos objetivos e da comunicação desses objetivos para todos os envolvidos com o curso.

Planejamento é citado pelos entrevistados por ainda não ter alcançado um patamar razoável para conseguir a excelência em cursos a distância. Atrasos ocorrem, principalmente ao se lidar com a máquina pública, com atrasos de recursos financeiros, mas não podem ser constantes. Por exemplo, a licitação da impressão de um material didático pode não ter nenhum candidato em um momento inicial, sendo necessária uma nova chamada, atrasando assim todo o calendário planejado.

Alunos e tutores reclamam da mudança de datas e horários de provas e atividades. Planejamento é algo a ser cumprido e controlado. Um dos problemas enfrentados nos cursos é a utilização dos polos por várias instituições e cursos, gerando choques de horários e interesses. Nesse momento, caso não seja feito um acordo entre os cursos, a instituição e os órgãos superiores devem intermediar as negociações. No entanto, isso deve ser feito antes do começo de cada semestre para que as datas, os horários e os locais não sejam empecilhos e fatores desmotivadores aos alunos.

Porém, todo o planejamento só será completo se agregar a função de controle. Esse é essencial para a correção de erros durante e depois dos processos, gerando informações para os novos planejamentos. Dessa forma, estar-se-á desenvolvendo o aprendizado organizacional.

Também é necessário na gestão do curso planejar a preparação do aluno para estudar a distância. Essa preparação deve começar já na divulgação do curso, antes da inscrição do vestibular, informando carga-horária, atividades previstas, tempo do curso, etc.
Após ser aprovado no vestibular, o trabalho de integração do aluno e sua preparação ao método de ensino devem começar. Isso requer da gestão do curso um dispêndio maior de tempo e de recurso nessa etapa, que, de acordo com os autores da área de evasão, é o momento no qual ocorre o maior número de desistências. Ainda é importante desmistificar a ideia de que a educação a distância é uma modalidade mais fácil do que o presencial. O preconceito quanto à modalidade continuará existindo enquanto ideias como essas não forem esclarecidas. Neste caso é importante um trabalho alinhado dos gestores, dos professores e dostutores presenciais e a distância.

Assim, é importante desenvolver o agir educacional no aluno (além do professor, que deverá também ser previamente capacitado). No agir educacional, o aluno deve desenvolver a autonomia, como proposto por Paulo Freire e o aprendizado individual de Piaget. Além disso, ele deve desenvolver também o agir comunicativo, principalmente por meio das tecnologias que utilizará durante o curso.

É necessário ressaltar novamente que essa preparação está voltada a um olhar mais crítico da educação, no qual o desenvolvimento está pautado em um curso de qualidade e em um aluno que tenha autonomia e autoridade do argumento, conforme Demo (2004). Não se espera que os profissionais desses cursos sejam meros reprodutores de conhecimento, mas sim profissionais críticos.

Uma das formas de desenvolver mais essa criticidade é por meio de pesquisas. Não há no momento projetos de pesquisas que envolvam os estudantes a distância. Essa é uma iniciativa que corrobora com o objetivo anterior, de fazer o aluno se sentir parte da universidade com o intuito de desenvolver novas competências no futuro profissional.

Isso corrobora com a teoria de Demo (2004) e Freire (2006, 2001, 1992, 1970), ao envolver a prática na educação para auxiliar o aprendizado e as competências dos alunos.

Nesse momento, mesmo o curso sendo a distância, o contato inicial com um professor ou gestor do curso pode auxiliar na geração de confiança entre o aluno e o curso. Também incentiva o aluno a fazer parte da instituição.

Aliás, essa foi uma das questões discutidas com alunos, gestores e tutores. Infelizmente, nem todos os 
alunos a distância se sentem parte da instituição. Para alguns, o ato de passar no vestibular, já foi suficiente para fazer parte da instituição. Outros se sentiam como alunos no polo X, e não da UFSC. Esse fato foi inclusive discutido em um fórum de coordenadores de curso como um dos possíveis fatores para a evasão.

Para minimizar esse fato, a gestão deve promover parcerias com centros acadêmicos, diretório de estudantes e pró-reitorias para levar aos alunos atividades $e$ produtos que auxiliem nessa identificação com a instituição. Pode ser uma carteirinha de estudante, uma camiseta, ou mesmo fazer parte dos órgãos estudantis. A solicitação de carteirinha de estudante foi uma das maiores reivindicações iniciais dos estudantes.

Pode-se também criar uma biblioteca on-line disponibilizando informações sobre congressos, trabalhos de conclusão de curso (monografias) sobre EaD e outros temas do curso e dos alunos que já fizeram o curso.

Após essas atividades, os alunos estarão preparados para iniciar o curso e aproveitar as oportunidades que serão oferecidas, como cursos, palestras, estágios, etc.

Outro ponto envolvendo a gestão dos cursos é o tempo de respostas. Na tutoria, esse tempo de resposta é padronizado, em até 48 horas. Mas em relação à coordenação não há uma padronização, e essa é uma das reclamações dos polos e de alguns alunos. Devido ao fato de demorarem a responder algum e-mail, acaba-se utilizando o telefone para a comunicação, o qual pode facilitar no pronto-atendimento, mas não armazena as informações. O uso do e-mail neste caso seria melhor, mas para isso é necessário que sejam estabelecidos prazos, ou pelo menos uma resposta breve para informar que o problema está sendo resolvido.

Em relação à evasão dos alunos, foi feito um formulário para preenchimento quando ocorrer a desistência. Esse é um procedimento novo que ainda não está em pleno funcionamento, porém, um simples formulário pode gerar várias informações pertinentes sobre o assunto para evitar futuras desistências.

A coleta de informações sobre o curso pode ser ainda ampliada para os alunos frequentes ao curso, com a avaliação do curso, a disciplina, o material, o professor, a metodologia, etc. A UFSC desenvolveu o Sistema de Acompanhamento e Avaliação de Disciplinas (SAAD), que avalia alguns desses elementos, mas com baixa participação dos alunos atualmente.
Cabe destacar que gerar os dados não basta, é preciso que haja uma sistematização de análises das informações e um compartilhamento dos resultados, que podem auxiliar não apenas a gestão deste curso, mas, se for compartilhados e comparados com o de outras instituições, podem auxiliar no desenvolvimento de universidades mais cooperativas e voltadas ao aprimoramento da ciência.

Tendo como foco a interpretação dos dados, pode-se notar que os agentes do curso têm internalizado suas competências e funções, mas não foi percebido por parte de alguns entrevistados uma visão holística do curso. Ou seja, os participantes conhecem bem sua atividade, mas, muitas vezes, eles possuem uma visão alienada, não percebem todo o conjunto $e$ as características que fazem parte do curso, eles não têm ideia de sua complexidade. Essa visão holística só foi percebida em maior grau por parte dos gestores do curso. Talvez uma das causas desse fato relatado seja a comunicação, que, mesmo tendo vários canais e meios, as informações e o conhecimento sobre o funcionamento total do curso não é repassado.

Essa visão holística pode auxiliar os alunos, por exemplo, a entenderem certas características do curso e suas decisões. Por exemplo, alguns não sabem quantos cursos e universidades atuam em seu polo de ensino, fazendo com que as vezes um troca de calendário (data), que foi negociada com outro curso, seja entendida como falta má gestão do curso.

Analisando os fatores capacitadores para a criação do conhecimento organizacional de Nonaka e Takeushi (1997), tem-se que, em relação à intenção, ela está pautada no planejamento que deve ser constituído. Esse ponto acontece, mas ainda precisa ser desenvolvido de melhor forma.

Sobre a autonomia, há um espaço limitado para o exercício desse fator, o qual deve ser ampliado. Da mesma forma, a flutuação e o caos criativo tem pouca iniciativa da gestão do curso para o seu desenvolvimento.

A redundância do conhecimento está sendo trabalhada, por meio de mapeamento de processos, e delimitação das tarefas. Mas não há sistematização de compartilhamento de informação entre os agentes. Já a variedade de requisitos é uma constante dentro da organização, já que é um dos fatores mais discutidos, devido à complexidade da organização. 
[...] eu digo que tanto o presencial quanto o a distância podem ser tão bom quanto, desde que a gente enquanto professor façamos a nossa parte bem como nós quanto alunos façamos, fazemos a nossa parte, de que maneira?, estudando, se dedicando, interagindo, trocando ideia, seja com o aluno, seja com o professor, seja com o tutor, mas fazendo com que a universidade passe, não seja um momento de passar em branco, talvez, a partir do momento que as pessoas entenderem que a universidade é uma baita de um centro de oportunidades, até mesmo pra construção profissional, eu acho que as pessoas vão se deparar de forma diferente. (GESTOR 1)

Por fim, resgata-se a discussão sobre a interação entre os envolvidos tanto na gestão, quanto com os alunos, tutores, polos etc. O compartilhamento, socialização, externalização de conhecimento devem ser constantes, e o aprimoramento do conhecimento de todos só é possível com essa interação e abertura para o aprendizado.

Dessa forma, apresenta-se a seguir um quadro com as principais forças e fraquezas do curso com uma visão de cada um dos paradigmas estudados.

\begin{tabular}{|c|c|c|}
\hline \multicolumn{2}{|r|}{ INTERPRETATIVISTA } & FUNCIONALISTA \\
\hline Força & $\begin{array}{l}\text { Percepção dos } \\
\text { agentes do curso } \\
\text { sobre o seu processo } \\
\text { e suas funções }\end{array}$ & $\begin{array}{l}\text { Busca pela eficiência do } \\
\text { processo. Tutoria estruturada } \\
\text { e decisões em comissões. }\end{array}$ \\
\hline Fraqueza & $\begin{array}{l}\text { Pouco conhecimento } \\
\text { holístico do curso. } \\
\text { Pouca interação. }\end{array}$ & $\begin{array}{l}\text { Falta de objetivos claros } \\
\text { para os envolvidos }\end{array}$ \\
\hline \multicolumn{2}{|r|}{ TEORIA CRÍtICA } & Gestão do Conhecimento \\
\hline Força & $\begin{array}{l}\text { Vários meios de } \\
\text { comunicação. }\end{array}$ & Mapeamento de processos. \\
\hline Fraqueza & $\begin{array}{l}\text { Necessidade de maior } \\
\text { desenvolvimento da } \\
\text { autonomia do aluno. } \\
\text { Pouco incentivo à } \\
\text { comunicação e o } \\
\text { desenvolvimento } \\
\text { de argumento. }\end{array}$ & $\begin{array}{l}\text { Espiral do Conhecimento. } \\
\text { Não há incentivo e } \\
\text { sistematização para } \\
\text { que o conhecimento } \\
\text { seja compartilhado e } \\
\text { disseminado. Falta de } \\
\text { armazenamento de } \\
\text { informações e decisões. }\end{array}$ \\
\hline
\end{tabular}

Quadro 3: Análise paradigmática com principais forças e fraquezas

Fonte: Elaborado pelos autores deste artigo

Percebe-se, nesse sentido, que, por meio de um olhar de cada um dos paradigmas, foi possível perceber pontos positivos e convergentes com o que os teóricos defendem nesse campo.

$\mathrm{Na}$ visão interpretativista, como a realidade é construída pelas pessoas e relações, buscou-se analisar suas falas, bem como a percepção da pesquisa em campo, em relação a essa realidade, destacando que muitos agentes não conhecem todo o funcionamento do curso e que há pouca interação, por exemplo, entre alunos e gestores a interação é muito baixa.

Já no funcionalista, busca-se sempre quantificar e objetivar a gestão. Dessa forma, foi percebido que há uma ênfase na eficiência do projeto, mas, as vezes, sem saber qual o resultado final, ou seja, sem eficácia.

Pela teoria crítica há vários meios possíveis de comunicação, mas para que ela seja plenamente utilizada é necessário que se desenvolva o argumento dos agentes. A autonomia, tanto dos alunos como tutores, polos, entre outros, ainda é um fator a ser desenvolvido pelo curso.

Na gestão do conhecimento, foi visto que muitos processos dentro do curso já estão mapeados, já que é possível perceber, no paradigma interpretativistas, que os agentes conhecem suas funções. Mas o conhecimento ainda é pouco socializado e compartilhado, além de não se ter armazenamento de muitas decisões do curso, ficando estas somente no conhecimento tácito dos participantes, mas com uma rotatividade alta, por exemplo, de tutores, fator altamente prejudicial ao curso, seja qual for.

Após essa explanação da teoria multiparadigmática, a seguir são abordadas as considerações finais e as recomendações para trabalhos futuros.

\section{Considerações Finais}

Quanto ao objetivo de desenvolver uma construção teórica sobre a gestão de um curso a distância na esfera pública que favoreça permanência dos alunos por meio da efetividade de processos com foco no conhecimento, fazendo-se uma avaliação da abordagem multiparadigmática utilizada, é possível perceber que o paradigma mais atuante no curso é o funcionalista, por meio da busca da efetividade.

Há poucos sinais do paradigma da teoria crítica nas ações do curso, mas, na fala dos entrevistados, principalmente em relação às dificuldades do curso $e$ 
à preparação do aluno, pôde-se perceber claramente a atuação desse paradigma, por meio (da falta) da ação comunicativa de Habermas nas dificuldades do curso $e$ da necessidade de autonomia dos alunos (FREIRE, 2006, 2001, 1992, 1970; DEMO, 2004; PIAGET, 1970; VYGOSTSKY, 2009), principalmente no momento de preparação deste aluno para o estudo na modalidade a distância. Resgatando as ideias de Piaget (1970), são necessários os momentos coletivos e interação, mas o aprendizado é individual. São esses pontos que precisam ser abordados na preparação dos alunos. Além disso, também a inserção da prática e do aluno visualizar aquele novo conhecimento em seu cotidiano, utilizando elementos de sua vivência e experiência, principalmente em se tratando de um público adulto, que pode contribuir muito nesse sentido.

Em relação à teoria fundamentada em dados desenvolvida, o ponto principal percebido foi a estrutura de gestão e da variabilidade de opções disponibilizadas aos alunos. A estrutura colegiada, dividida em coordenações é essencial para um funcionamento eficiente. Além disso, uma estrutura própria de equipe editorial dinamiza o processo e auxilia na manutenção da qualidade do material oferecido. Há ainda a estrutura da UFSC, como o Laboratório de Ensino a Distância (LED), que viabiliza as aulas gravadas e as videoconferências.

Em complemento, na visão da autora, a principal estrutura disponibilizada ao aluno é a tutoria. De acordo com o desenho do curso, a tutoria a distância (sediada na UFSC), atua 12 horas por dia, de segunda a sexta-feira para o atendimento ao aluno, mas esse atendimento não é apenas de conteúdo, como visto na literatura, o lado humano, afetivo e de relacionamento é tão importante quanto as funções de corrigir, tirar dúvidas, etc. O tutor em muitos momentos é o elemento de confiança que o aluno tem na universidade.

O papel da gestão neste caso é construir um ambiente favorável ao trabalho dos tutores, pois são eles que normalmente atenderão os alunos quando algum problema de gestão surgir, por exemplo, uma mudança de calendário. Cabe ressaltar esse ponto: devido à baixa remuneração e a uma visão distorcida do tutor não condizentes com as funções que eles realizam, problemas como a alta rotatividade são frequentes. Um graduado em Administração, muitas vezes com mestrado/doutorado, não vai permanecer em um local com uma remuneração de $\mathrm{R} \$ 600,00$ (seiscentos reais) por quatro horas de trabalho diário, principalmente se não houver perspectivas de crescimento e de desenvolvimento.

No início do curso, devido a esses valores e à carga horária exigida, o curso optou por utilizar alunos das últimas fases do curso de administração presencial como tutores. Eram selecionados os melhores alunos (alto índice de aproveitamento na disciplina) e a rotatividade era muito baixa nesse período. Além disso, muitos dos tutores se identificaram com o trabalho, despertando um gosto por atividades relacionadas à docência, agora eles são alunos de mestrado e de doutorado. Essa iniciativa, apesar de elogiada e respeitada por outros alunos, não foi aceita pelo MEC. Os novos tutores têm suas capacidades e competências e diploma, mas infelizmente muitas vezes não têm o comprometimento e a identificação que se tinha anteriormente. Essa não é uma questão de crítica aos novos tutores, mas simplesmente um resgate do pensamento da autora (e de alguns entrevistados) sobre esse processo.

O que merece uma boa reflexão é a busca de efetividade nos cursos. Resgata-se que para ser efetivo é necessário ser eficiente (meios) e eficaz (objetivo). Foi percebido que os meios tiveram uma maior atenção da gestão. Para a eficácia, é necessária que os objetivos estejam claros para todos os envolvidos que estejam comprometidos. No início do curso, esse conhecimento dos objetivos era mais claro, mas com a rotatividade inerente ao curso e com seu crescimento nem todos os agentes conseguiram internalizar esse objetivo, podendo esse fato impactar no comprometimento com o curso.

O ditado popular já relata que "errar é humano", o que não se pode é persistir nos erros. Em uma gestão, com vários participantes e com rotatividade, para que esse ditado não seja verdadeiro, é necessária uma consistente gestão do conhecimento. Isso permite que o conhecimento adquirido seja armazenado, disseminado e compartilhado. No contexto do curso, pode ser que o gestor, ou o tutor, não saiba que esse já surgiu esse, mas é necessário lembrar que o aluno, que acompanha o processo de gestão desde o seu início, perceberá que novamente ocorreu o mesmo problema, isso pode fazer com que o aluno tome uma 
decisão diferente da que tomou anteriormente por não ter esse armazenamento.

Faz-se ainda uma reflexão sobre o objetivo da educação superior, qualitativo ou quantitativo. A maioria dos discursos sempre foca na qualidade do ensino, da aprendizagem e, consequentemente, da formação do aluno.

Encerra-se, dessa forma, as considerações finais desta pesquisa, ressaltando que a pesquisa e seus resultados são uma tentativa de auxiliar na qualidade da gestão da modalidade a distância. Espera-se também colaborar com as pesquisas voltadas à gestão da permanência e à evasão dos estudantes.

\section{REFERÊNCIAS}

\section{ABRAEAD. Anuário Brasileiro Estatístico de}

Educação Aberta e a Distância. 3. ed. São Paulo: Instituto Monitor, 2007.

BANDEIRA DE MELLO, Rodrigo; CUNHA, Cristiano José C. de Almeira. Grounded Theory. In: GODOI, Christiane K.; BANDEIRA DE MELLO, Rodrigo; SILVA, Artielson B. da (Org.). Pesquisa qualitativa em estudos organizacionais: paradigmas, estratégias e métodos. São Paulo: Saraiva, 2006.

BELLONI, Maria Luiza. Ensaio sobre a educação a distância no Brasil. Educ. Soc., Campinas, v. 23, n. 78, abril, 2002. Disponível em: <http://www. scielo.br/scielo.php?script $=$ sci_arttext\&pid $=$ S0101$73302002000200008 \& \operatorname{lng}=e n \& n r m=i s o>$. Acesso em: $1^{\circ}$ maio 2009.

\section{BIAZUS, Cleber Augusto. Sistema de fatores que} influenciam o aluno a evadir-se dos cursos de graduação na UFSM e na UFSC: um estudo no curso de Ciências Contábeis. Florianópolis, 2004. Tese. (Doutorado em Engenharia de Produção). Universidade Federal de Santa Catarina.

\section{CISLAGHI, Renato. Um modelo de sistema de} gestão do conhecimento em um framework para a promoção da permanência discente no ensino de graduação. Florianópolis, 2008. 258 f. Tese (Doutorado) Programa de Pós-Graduação em Engenharia e Gestão do Conhecimento, UFSC, Florianópolis - SC, 2008.

\section{DEMO, Pedro. Pesquisa e construção de} conhecimento: metodologia científica no caminho de Habermas. Rio de Janeiro: Tempo Brasileiro, 2004.

FARIA, Lilian Maria de Oliveira Faria; ALCANTARA, V. M.; GOIA, Carla Vasco. Índice e causas de evasão na modalidade a distância em cursos de graduação: estudo de caso. In: Universidad 2008 - VI CONGRESSO INTERNACIONAL DE EDUCAÇÃO SUPERIOR, 2008, Havana. Anais... II taller Internacional, 2008.

FREIRE, Paulo. Pedagogia da autonomia. 33. ed. Paz e Terra, São Paulo, 2006.

Educação e atualidade brasileira. 3. ed. São Paulo: Cortez; Instituto Paulo Freire, 2001.

Pedagogia da esperança: um reencontro com a pedagogia do oprimido. Rio de Janeiro: Paz e Terra, 1992.

Pedagogia do oprimido. Rio de Janeiro: Paz e Terra, 1970.

HABERMAS, Jurgen. A ética da discussão e a questão da verdade. 2. ed. São Paulo: Martins Fontes, 2007a.

Entre naturalismo e religião: estudos

filosóficos. Rio de Janeiro: Tempo Brasileiro, 2007b.

Consciência moral e agir comunicativo. Rio de Janeiro: Tempo Brasileiro, 2003.

Pensamento pós-metafísico: estudos filosóficos. 2. ed. Rio de Janeiro: Tempo Brasileiro, 2002.

LEWIS, Marianne W.; GRIMES, Andrew J. Metatriangulação: construção teórica com base em paradigmas múltiplos. In: CALDAS P. Miguel; BERTERO, Carlos O. Teoria das organizações. São Paulo: Atlas, 2007.

\section{NONAKA, Ikujiro; TAKEUCHI, Hirotaka. Criação} de conhecimento na empresa: como as empresas japonesas geram a dinâmica da inovação. 2. ed. Rio de Janeiro: Campus, 1997. 358p.

PACHECO, Andressa Sasaki Vasques. Evasão: análise da realidade do curso de graduação em Administração a distância da Universidade Federal de Santa Catarina. 2007. 136 f. Dissertação (Mestrado em Administração) 
- Programa de Pós-Graduação em Administração,

Universidade Federal de Santa Catarina, Florianópolis,

2007.

PIAGET, Jean. Psychologie et épistémologie. Paris:

Gonthier, 1970.

SOUZA, Irineu Manoel de. Causas da evasão nos cursos de graduação da Universidade Federal de Santa Catarina. Florianópolis, 1999. Dissertação (Mestrado em Administração). Universidade Federal de Santa Catarina, 1999.

STRAUSS, Anselm; CORBIN, Juliet. Pesquisa

qualitativa: técnicas e procedimentos para o desenvolvimento de uma teoria fundamentada. 2. ed. Porto Alegre: Artmed, 2008.

\section{UNESCO. Aprendizagem aberta e a distância:} perspectivas e considerações políticas educacionais. Florianópolis: Imprensa Universitária, UFSC, 1997.

VERGARA, Sylvia C.; CALDAS, P. Miguel. Paradigma interpretacionista: a busca da superação do objetivismo funcionalista nos anos 1980 e 1990. In: CALDAS P. Miguel; BERTERO, Carlos O. Teoria das Organizações. São Paulo: Atlas, 2007.

VYGOTSKY, Lev Semenovich. Pensamento e linguagem. [2009]. Disponível em: <http://www. futuroeducacao.org.br/biblio/pensamento_e_linguagem. pdf $>$. Acesso em: 28 nov. 2009. 